\title{
Artigo/Article
}

\section{Progressão da circulação do vírus do dengue no Estado da Bahia, 1994-2000}

\author{
Progression of dengue virus circulation in the State of Bahia, Brazil, 1994-2000 \\ Maria Suely Silva Melo ${ }^{1}$, Florisneide Rodrigues Barreto ${ }^{2}$, Maria da Conceição Nascimento Costa ${ }^{2}$, Vanessa Cristina \\ Morato $^{2}$ e Maria Gloria Teixeira ${ }^{2}$
}

\begin{abstract}
RESUMO
Introdução: A força da reemergência do vírus do dengue e a gravidade destas infecções colocaram esta doença na agenda de prioridades das instituições responsáveis pela proteção à saúde das populações. Aspecto importante para a compreensão da epidemiologia do dengue nos dias atuais refere-se ao conhecimento dos padrões da difusão espaço-temporal, entretanto são escassas as investigações que abordam esta questão. Este estudo descreve o processo de difusão do dengue no estado da Bahia, de 1994 a 2000. Métodos: Trata-se de estudo ecológico espaçotemporal, tendo como unidades de análise município, semana epidemiológica, mês, trimestre e ano. Procedeu-se construção da curva de tendência e realizou-se mapeamento seqüencial da ocorrência de dengue por município para o período. Resultados: Foram notificados 164.050 casos de dengue e a introdução desse vírus na Bahia, diferentemente de outros estados, se deu por um município de pequeno porte, constatando-se intermitência temporal e espacial nos registros de casos no início desta epidemia. Contudo, a partir de 1995 o processo de difusão da doença se deu de forma rápida e intensa. O vírus circulou em todas as zonas climáticas do estado o que revela o seu elevado poder de transmissão. A maior intensidade de detecção de casos e expansão territorial foi nas regiões úmidas e semi-úmidas do litoral, ideais para a sobrevivência e proliferação do vetor, e também, por serem mais densamente povoadas. Conclusões: Hipoteticamente, o padrão espaço-temporal intermitente de detecção de casos observado inicialmente, poderia permitir o controle da progressão da epidemia, caso houvesse ações de combate vetorial estruturadas.
\end{abstract}

Palavras-chaves: Dengue. Circulação viral. Difusão espaço-temporal.

\begin{abstract}
Introduction: The strength of the re-emergence of dengue virus and the severity of these infections put this disease in the priority agenda of the institutions responsible for protecting the health of populations. Important for understanding the epidemiology of dengue nowadays refers to the knowledge of the patterns of spatial-temporal diffusion, though there is few research addressing this issue. This study describes the process of dissemination of dengue in the state of Bahia, from 1994 to 2000. Methods: This ecological study space-time, with the units of analysis, county, epidemiological week, month, trimester and year. There has been construction of the trend line and has been mapping the sequential occurrence of dengue in the municipality for the period. Results: There were 164,050 reported cases of dengue and the introduction of this virus in Bahia, unlike other states, occurred on a small city, though there is intermittency in spatial and temporal records of cases at the beginning of this epidemic. The virus circulated in all climatic zones fact what highlight its high transmission power. The highest intensity of detection of cases and territorial expansion was in the littoral (zone humid and halfhumid) ideal area for the survive of the vector. Conclusions: Hypothetically, the intermittent space-time pattern initially observed, could have allowed the control of the progression of the epidemic, if structured action to vectorial combat was carried out.
\end{abstract}

Key-words: Dengue. Viral circulation. Space-time diffusion.

1. Faculdade de Medicina, Universidade Federal da Bahia, Salvador, BA. 2. Instituto de Saúde Coletiva, Universidade Federal da Bahia, Salvador, BA.

Endereço para correspondência: Dra. Maria da Glória Teixeira. R. Basílio da Gama s/n, Canela, 40110-170 Salvador, BA.

e-mail:magloria@ufba.br

Recebido para publicação em 10/09/2009

Aceito em 05/03/2010

\section{INTRODUÇÃO}

A gravidade das infecções causadas pelo vírus do dengue bem como a força da sua reemergência em vários continentes colocaram esta doença como prioridade na agenda das instituições nacionais e internacionais responsáveis pela proteção à saúde das populações. A existência de inúmeras lacunas no conhecimento científico à respeito de vários aspectos desta virose, particularmente, no que se refere a seus padrões epidemiológicos ${ }^{1}$ aponta para a necessidade de realizar investigações sobre o padrão de distribuição espaço-temporal, visando a obtenção de conhecimentos que contribuam para o aprimoramento das ações da prevenção destas infecções.

Os estudos epidemiológicos sobre dengue no Brasil, país onde esta doença se constitui um dos mais importantes problema de Saúde Pública ${ }^{2,3}$, têm abordado a sua distribuição espacial ${ }^{4,5}$ e intensidade da circulação viral apenas em espaços urbanos ${ }^{6-8} \mathrm{e}$ a tendência temporal para o país como um todo e regiões geográficas ${ }^{7}$. Entretanto, não analisam os padrões de difusão espaço-temporal intrarregiões.

Neste sentido, estudos sobre o comportamento da circulação viral no espaço e no tempo utilizandose unidades de análises mais desagregadas de modo a permitir a visualização da difusão do vírus, poderão identificar a existência de características especiais deste processo $^{9}$, particularmente entre municípios de uma mesma Unidade Federada. Este detalhamento poderá contribuir para a construção de modelos de predições mais acurados e, principalmente, para verificar se o diagnóstico precoce de casos, ou seja, o aprimoramento da vigilância epidemiológica possibilitará o uso dos instrumentos de prevenção já disponíveis de forma mais efetiva, mesmo considerando os limites impostos pelos recursos técnicos científicos atuais. Este estudo teve como objetivo identificar o padrão de progressão da circulação dos vírus do dengue no Estado da Bahia, no período de 1994 a 2000. 


\section{MÉTODOS}

Trata-se de estudo ecológico espaço-temporal, tendo como unidade de análise espacial o município. Semana epidemiológica, mês, trimestre e ano calendário foram as unidades temporais. Foram incluídos todos os municípios do Estado da Bahia que tiveram registro de casos de dengue no período de 1994 a 2000. Vale referir que os procedimentos adotados pela vigilância epidemiológica são padronizados para todos os municípios do estado, podendo se assumir que a qualidade dos registros não é muito diferente entre os mesmos.

O Sistema de Informação de Agravos de Notificação (SINAN), da Secretaria de Saúde do Estado da Bahia, foi a fonte de dados sobre casos notificados de dengue. As informações sobre área e população dos municípios e classificação das mesorregiões da Bahia foram obtidas da Fundação Instituto Brasileiro de Geografia e Estatística (FIBGE). A malha rodoviária e a tipologia climática (classificação de Thornthwaite) foram oriundas da Superintendência de Estudos Econômicos e Sociais da Bahia (SEI) e o número de imóveis inspecionados e positivos para o Aedes aegypti foram extraídos do sistema de informações do Programa de Febre Amarela e Dengue da Fundação Nacional da Saúde (FAD/ FUNASA).

Constituíram-se em variáveis e indicadores: número de casos notificados por semana epidemiológica por município; taxa de detecção do dengue por município (número de casos notificados por semana epidemiológica, dividido pela população X 100.000); índice de infestação predial (IP) do Aedes aegypti por município (número de imóveis positivos x 100 divididos pelo número de imóveis inspecionadas); densidade demográfica por município, para o período do estudo (número total de habitantes, dividido pela sua área geográfica em $\mathrm{km}^{2}$, utilizando como referência a população do censo do IBGE de 1996).

Comparou-se a magnitude das taxas por município e verificou-se o padrão temporal das curvas do coeficiente de detecção de casos. Os municípios foram codificados como positivos (quando havia notificação de casos de dengue) e negativos (sem notificação). Este banco foi então integrado em uma base geocodificada referente aos municípios do Estado da Bahia no programa Tabwin 32, realizandose mapeamentos seqüenciais dos casos de dengue, por municípios atingidos, por semana epidemiológica, para todo o período do estudo, o que permitiu se obter a representação gráfica espaço-temporal da progressão viral.

Mediante inspeção visual dos mapas obtidos, observou-se o padrão de progressão espaço-temporal dos casos de dengue na Bahia, semana a semana, desde o início da epidemia em 1994. Posteriormente, na medida em que vários municípios iam sendo atingidos e, concomitantemente, outros mantinham a circulação viral, caracterizada pelo registro constante de novos casos, as taxas de detecção de casos dos municípios foram sendo consolidadas nos mapas por trimestre e ano. Procedeu-se a superposição dos mapas obtidos do estudo da progressão da circulação do vírus do dengue com os da malha rodoviária principal e da tipologia climática do Estado da Bahia, visando observar a participação destes fatores no processo de dispersão do dengue.

Para identificar os padrões de distribuição da magnitude das taxas de detecção de casos de dengue, logo após a detecção da doença nos municípios, estas foram distribuídas segundo ordem decrescente daquele indicador, tomando-se como referência o ano de 1996, por ter sido o de maior taxa de detecção para o estado como um todo, no período do estudo. A seguir, mediante inspeção visual das taxas apresentadas em cada município, verificou-se os padrões apresentados, classificando-os da seguinte forma: Padrão 1: quando o município apresentou um único pico epidêmico; Padrão 2: dois picos epidêmicos em anos consecutivos; Padrão 3: três picos epidêmicos em anos consecutivos; Sem padrão: nenhum dos padrões anteriores.

Para os municípios nos quais a FUNASA desenvolvia ações do Programa de Combate ao Aedes aegypti, estimou-se os IP por trimestre, calculou-se os valores máximos e mínimos, a média e a mediana deste indicador, considerando o valor máximo trimestral encontrado de cada município para cada ano. Posteriormente, calculou-se no programa SPSS os Coeficientes de Correlação de Pearson entre a taxa de detecção de dengue e os IP por município, ambos por trimestre. Por fim, as taxas semanais de detecção de casos de dengue foram representadas em um gráfico de linha visando observar a sazonalidade da doença para o Estado da Bahia como um todo.

\section{RESULTADOS}

O programa de combate vetorial do Estado da Bahia, no período desse estudo, não estava estruturado em todos os municípios, de modo que os levantamentos de índices entomológicos (LI) da Secretaria da Saúde do Estado da Bahia não abrangiam todo o estado. Em 1994, apenas 38 deles possuíam registro deste indicador. A partir de então, foi ocorrendo expansão gradativa das ações do programa e em 1999 já se tem o LI de 351 (84,6\%) dos 415 municípios da Bahia. No ano de 1994, as medidas de IP dos municípios da região Sul do estado que dispunham de informações, variaram de $0,24 \%$ (Itajuípe) a 28,6\% (Prado), sendo os maiores valores encontrados em municípios próximos a Itagimirim, onde os primeiros casos de dengue foram detectados. Nos dois últimos trimestres o IP desse município foi de $9,7 \%$ e 1,98\%. Feira de Santana, que foi o primeiro município a apresentar casos de dengue longe da região Sul, também apresentou altas taxas do IP durante todo o ano de 1994 (1,3\% no primeiro trimestre, $9,6 \%$ no segundo, $14,1 \%$ no terceiro e $12,8 \%$ no quarto).

No período de 1994 a 2000, foram notificados 164.050 casos de dengue no Estado da Bahia, sendo 1996 o ano que mais contribuiu com este montante (45.866 casos notificados), cuja taxa de detecção alcançou 365,7/100.000 habitantes. Do total de municípios do estado, apenas 36 (8,7\%) não notificaram casos de dengue durante todo o período. No primeiro ano de epidemia, 4,8\% (20) dos municípios foram atingidos e em 1997 observou-se o maior contingente, com 73,3\% (304) dos municípios atingidos (Tabela 1). No final de janeiro de 1994, foram notificados os quatro primeiros casos de dengue na Bahia, no município de Itagimirim ituado na mesorregião Sul do estado. Nas semanas epidemiológicas 12 e 13, não houve nenhuma notificação e só a partir da $14^{\mathrm{a}}$ semana, foram diagnosticados casos em Belmonte e, duas semanas após, em Eunápolis, ambos contíguos a Itagimirim. Ocorreu uma intermitência temporal e espacial nos registros no início da epidemia, entre a $4^{\mathrm{a}} \mathrm{e}$ a $26^{a}$ semana epidemiológica. Somente no mês de junho de 1994 (26 semana), a circulação viral atingiu a mesorregião Centro Norte (município de Feira de Santana), situada a $508 \mathrm{~km}^{2}$ de Itagimirim, 
TABELA 1 - Casos notificados e taxa de detecção do dengue, número e percentual de municípios atingidos. Estado da Bahia, 1994 a 2000.

\begin{tabular}{lcccc}
\hline & & & \multicolumn{2}{c}{ Municípios com dengue } \\
\cline { 4 - 5 } Ano & Casos de dengue & Taxa de detecção & $\mathrm{n}^{\circ}$ & $\%$ \\
\hline 1994 & 1.974 & 15,84 & 20 & 4,6 \\
1995 & 32.487 & 256,90 & 110 & 21,0 \\
1996 & 45.866 & 365,70 & 180 & 30,3 \\
1997 & 42.969 & 338,10 & 304 & 42,2 \\
1998 & 21.176 & 164,80 & 297 & 41,7 \\
1999 & 7.972 & 61,40 & 222 & 34,9 \\
2000 & 11.606 & 88,80 & 253 & 37,9 \\
\hline
\end{tabular}

Fonte: DIVEP/ SESAB

no sentido nordeste do estado, onde as notificações passaram a ser registradas também de forma intermitente. Uma semana depois, um único caso foi notificado no município de Candeias situado na mesorregião Metropolitana do estado. Neste mesmo período, os casos começaram a ser diagnosticados em vários municípios da mesorregião Sul e, embora não se tenha observado continuidade das notificações, esta região concentrou o maior número de casos de dengue no primeiro ano de epidemia. No período compreendido entre a $28^{a}$ e a $45^{\text {a }}$ semanas epidemiológicas, a virose parece ter permanecido mais restrita aos municípios do extremo Sul. O vírus só alcançou a mesorregião Nordeste no final de 1994, quando surgiu um caso na semana $45^{\mathrm{a}}$ e outro na $52^{\mathrm{a}}$, nos municípios de Nova Soure e Santa Luz, respectivamente. Neste ano, a maior taxa de detecção para o estado como um todo (1,3/100.000 habitantes) ocorreu na semana 47 (novembro) com 158 notificações ( 0,9 por 100.000 habitantes).

Em 1995, a taxa de detecção de casos para o estado como um todo foi discretamente mais elevada (0,4 por 100.000 habitantes) que as das últimas semanas de dezembro do ano anterior, e a distribuição da doença manteve-se nas mesmas mesorregiões citadas em 1994, acrescentando-se casos em Santana, município situado no Extremo Oeste da Bahia, que logo na primeira semana de 1995 alcança taxa de detecção de 34,8/100.000 habitantes. Ainda no mês de janeiro deste ano, o dengue se expandiu para a mesorregião do Vale do São Francisco (Juazeiro) e mesorregião Centro Sul (Caetité, Brumado e Itapetinga) e os registros desta expansão territorial também não foram temporalmente contínuos. Foi na $17^{\mathrm{a}}$ semana epidemiológica de 1995, que a taxa de detecção de dengue na Bahia atingiu o pico máximo de todo o período deste estudo (29,8 por 100.000 habitantes), com 3.765 casos registrados, e a taxa média daquele ano para o estado como um todo foi de 256,9/100.000 habitantes.

A inspeção visual da distribuição espacial de casos de dengue no território baiano, em 1995, evidencia que as sedes das cidades dos municípios que se situam no eixo Sul-Norte, cortado pela Rodovia BA 101 desde Mucuri (Sul) até Cícero Dantas (mesorregião Nordeste), foram paulatinamente sendo atingidas pela doença. Salvador, capital do estado, só tem registro de casos no banco oficial da vigilância epidemiológica da Secretaria Estadual de Saúde a partir da $3^{\text {a }}$ semana epidemiológica, observando-se que a ocorrência é relativamente elevada (12.077 casos durante o ano de 1995), e só comparável a de Feira de Santana (10.392 casos) que apresentou o maior risco de adoecer naquele ano (2.368, 6 casos detectados por 100.000 habitantes), embora a mesorregião Sul tenha se mantido com o maior número de municípios acometidos. O total de notificações em 1995 foi de 32.487.

Houve um crescimento exponencial de casos de dengue em 1995, como se visualiza na curva epidêmica do estado (Figura 1), iniciando no final de fevereiro, atingindo seu maior pico na $17^{\mathrm{a}}$ semana e, a partir de junho ( $24^{\mathrm{a}}$ semana). Verifica-se então acentuado decréscimo da taxa de detecção (1,7 casos por 100.000 habitantes), que muitos municípios deixaram de registrar casos, e que em dezembro, apenas três municípios (Salvador, Nova Soure e Santana) apresentaram notificações da doença.

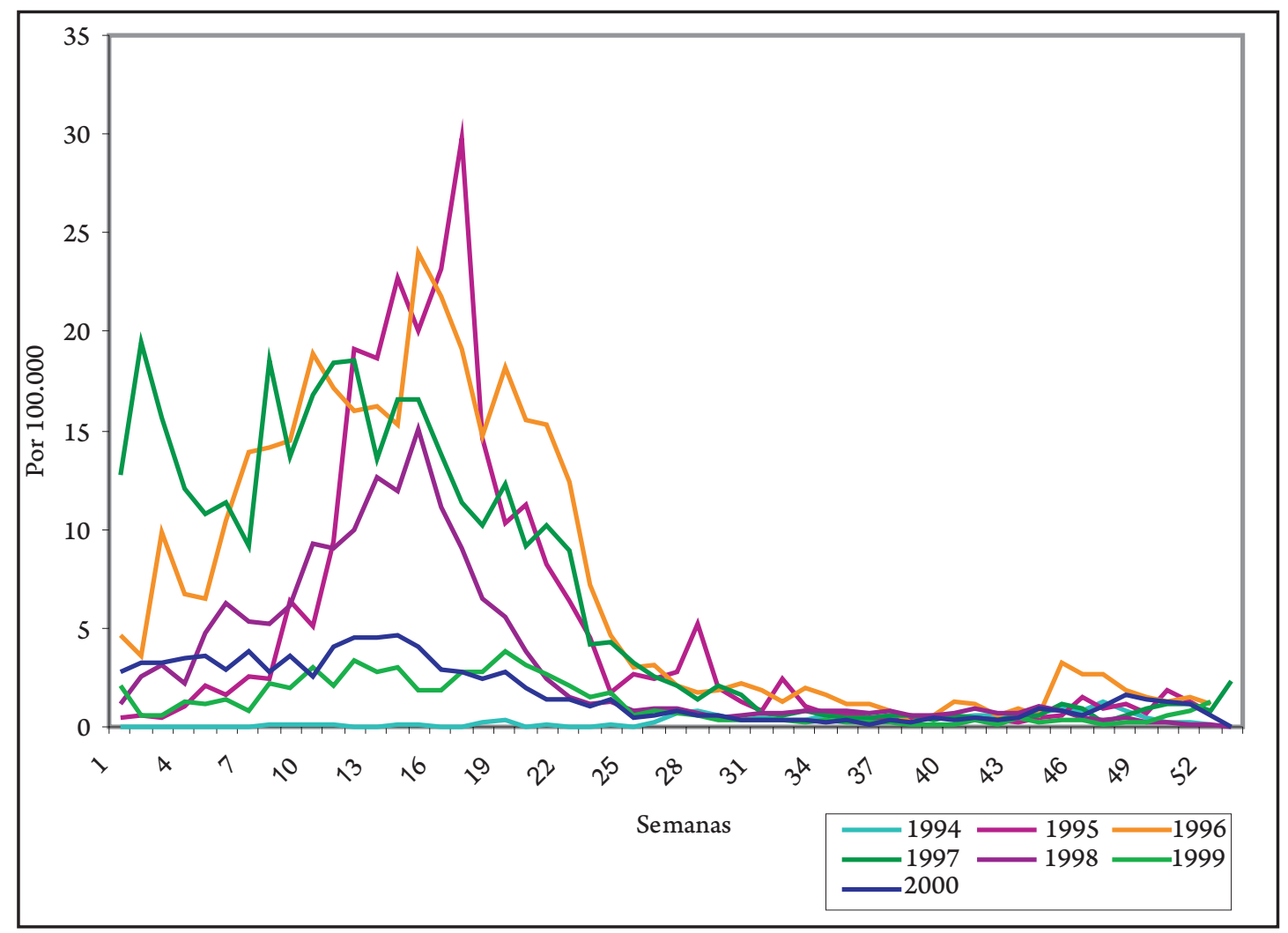

FIGURA 1 - Taxa de detecção de dengue (por 100.000 habitantes) por semana epidemiológica. Bahia, 1994 a 2000. 
A dispersão do vírus do dengue no território baiano continuou em 1996, e nas sete primeiras semanas deste ano têm-se casos notificados em seis das sete mesorregiões do estado (Sul, Centro Sul, Metropolitana, Nordeste, Centro Norte e Vale do São Francisco), enquanto a mesorregião Extremo-Oeste só começou a notificar na $9^{a}$ semana epidemiológica (Santa Maria da Vitória e Malhada). Também nesta área, o início das notificações tem caráter intermitente até a $21^{\underline{a}}$ semana epidemiológica. Salvador notificou casos durante todo este ano e os municípios situados nas mesorregiões Vale do São Francisco, Centro-Sul e Sul Baiano, também, registraram casos na maioria das semanas epidemiológicas. Itabuna, Ilhéus, Feira de Santana e Salvador notificaram 24.736 casos no ano, correspondendo a 54\% do total de notificações do estado (45.866). Assim, em 1996, a taxa média de detecção de casos para o estado alcançou o ápice do período de estudo com 365,7 por 100.000 habitantes, embora o maior pico epidêmico por semana epidemiológica tenha sido de 24/100.000 habitantes, na $15^{\underline{a}}$ semana.

Em 1997, a taxa de detecção, já se mostrou elevada na segunda semana epidemiológica de janeiro que foi o pico máximo deste ano (2.477 casos e taxa de detecção de 19,5/100.000 habitantes) e, embora tenha havido acréscimo, mantém-se em patamar acima de 9/100.000 habitantes até final de maio. A taxa média anual foi de 338,1 casos detectados por 100.000 habitantes. As notificações foram provenientes de municípios de todas as mesorregiões do estado da Bahia, na maioria situados ao longo da BR-101.

A semelhança dos anos anteriores, em 1998, a curva de tendência temporal do dengue aumenta progressivamente a partir da primeira semana de janeiro, com registros simultâneos em municípios de todas as mesorregiões do Estado da Bahia, chegando ao pico máximo na $15^{\mathrm{a}}$ semana com 1.933 casos notificados e taxa de detecção máxima de 15/100.000 habitantes; e, por volta da semana 20, as notificações passaram a decrescer mais acentuadamente. Porém, os municípios com registro, em sua grande maioria, foram os que ainda não tinham apresentado circulação do vírus nos anos anteriores, como Paratinga (mesorregião Vale São Francisco), Uauá (mesorregião Nordeste), Carinhanha (mesorregião Extremo Oeste) e outros. A mesorregião Sul apresentou, na $10^{\mathrm{a}}$ semana daquele ano, a maior concentração de municípios atingidos simultaneamente. Em dezembro ( $51^{\mathrm{a}}$ semana), poucos municípios do Centro Sul e Sul notificaram casos e na semana 53, houve apenas um município com casos de dengue notificados (Santa Luz, no Nordeste Baiano).

Os anos de 1999 e 2000 foram de baixa detecção de dengue (máximo de 3,8 e 3,5/100.000 habitantes, respectivamente), embora as taxas tenham sido discretamente mais elevadas no primeiro semestre, com início de declínio das notificações entre as semanas 21 e 24, nestes dois anos. Os registros de dengue foram provenientes de 253 municípios, dispersos nas sete mesorregiões, mantendo um padrão pontilhado em todo o estado, sendo poucos contíguos, o que ocorreu mais nas mesorregiões Centro Sul, Centro Norte e Metropolitana. No último ano do período deste estudo (2000), apenas dois municípios chegaram até a semana 52 (Salvador e Itabuna) com registro de casos. O máximo de notificações nestes dois últimos anos ocorreu na semana quatorze do ano 2000, com 603 casos e taxa de detecção de 4,6 por 100.000 habitantes.

A distribuição espacial dos casos notificados de dengue no período estudado pode ser observada na Figura 2. Entre os 258 municípios que, no período de 1994 a 2000, apresentaram magnitude das taxas de detecção de casos de dengue, definida de acordo com os critérios adotados, 47,3\% e 43,8\%, respectivamente, apresentaram uma e duas alças epidêmicas imediatamente após o início da detecção

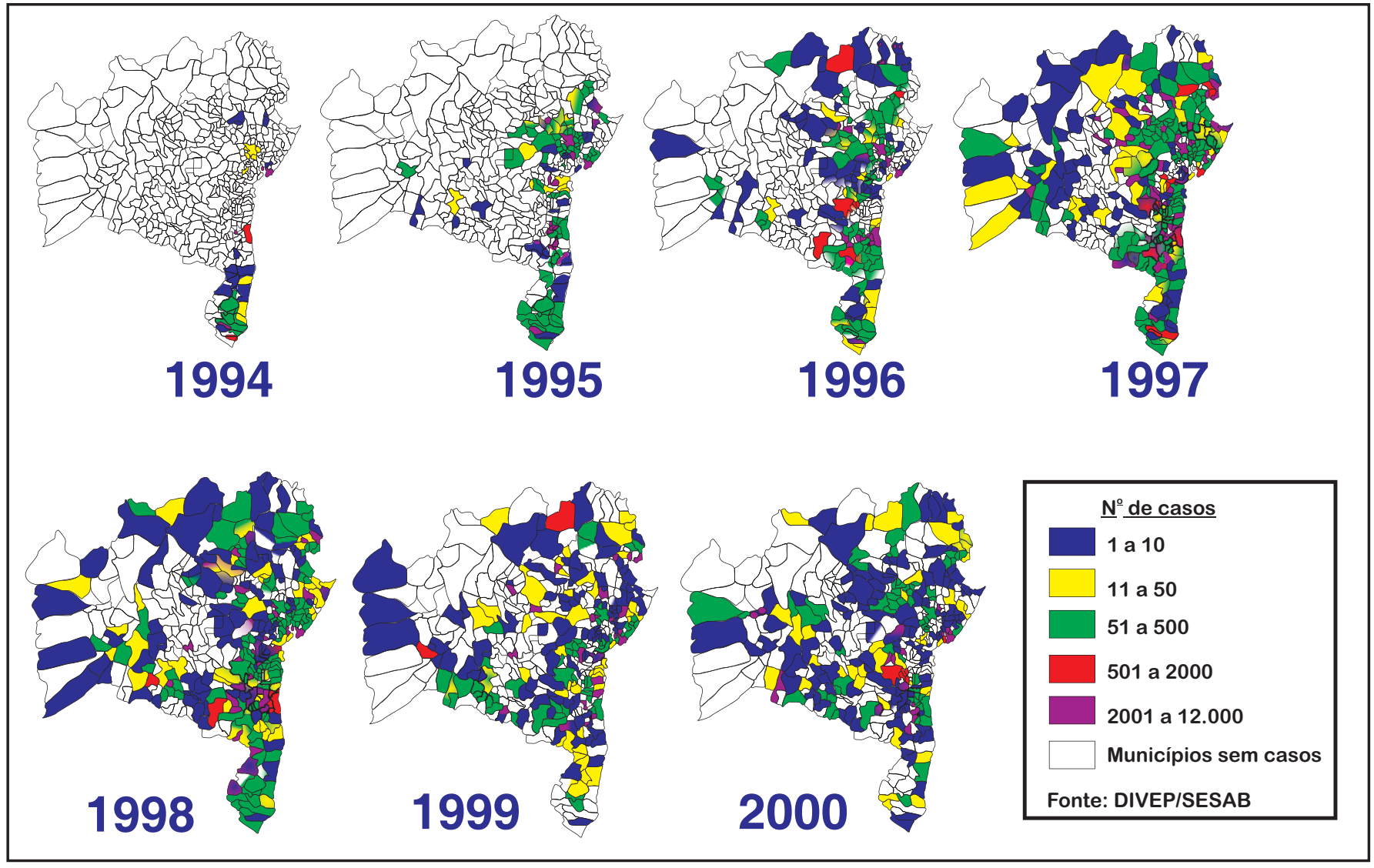

FIGURA 2 - Distribuição espacial dos casos notificados de dengue no Estado da Bahia, 1994 a 2000. 
de casos, enquadrando-se, portanto, nos padrões 1 e 2 . Não foi possível definir um padrão para $31,9 \%$ dos 379 municípios que notificaram casos de dengue no período.

Os municípios com maiores taxas de detecção de casos foram aqueles mais urbanizados e com maior densidade populacional, tais como Salvador, Cruz das Almas, Santo Antônio de Jesus, Lauro de Freitas, Simões Filho, Madre Deus, Feira de Santana, Conceição do Jacuípe, Itabuna e Ilhéus. O vírus se disseminou pelas cidades situadas ao longo dos principais troncos rodoviários federais (BR-101, BR-407, BR-242, BR-116, BR-415) e estaduais (BA-263, BA-262 e BA-052), e a dispersão mais intensa se deu pela BR-101, rodovia relativamente próxima do litoral, onde o clima é mais úmido e quente.

Verificou-se correlação positiva e significante entre as taxas de detecção de dengue e IP na grande maioria dos trimestres de todos os sete anos do estudo. Foram exceções: $1^{\circ}$ trimestre de 1998; $2^{\circ}$ trimestre de 1996 (boderline) e 1998; $3^{\circ}$ trimestre dos anos de 1994 e 1996; $4^{\circ}$ trimestre 1995 e 1999 (Tabela 2).

TABELA 2 - Coeficiente de correlação $(r)$ entre índice de infestação predial e taxa detecção do dengue. Estado da Bahia, 1994 a 2000.

\begin{tabular}{lcccc}
\hline & \multicolumn{4}{c}{ Coeficiente de correlação } \\
\cline { 2 - 5 } Ano & $1^{\circ}$ trimestre & $2^{\circ}$ trimestre & $3^{\circ o}$ trimestre & $4^{\circ}$ trimestre \\
\hline 1994 & - & $0,54^{*}$ & 0,18 & $0,37^{*}$ \\
1995 & $0,21^{*}$ & $0,32^{*}$ & $0,19^{*}$ & 0,03 \\
1996 & $0,24^{*}$ & 0,13 & $-0,01$ & $0,27^{*}$ \\
1997 & $0,27^{*}$ & $0,38^{*}$ & $0,18^{*}$ & $0,16^{*}$ \\
1998 & $0,11^{*}$ & 0,03 & $0,19^{*}$ & $0,10^{*}$ \\
1999 & $0,10^{*}$ & $0,25^{*}$ & $0,26^{*}$ & 0,03 \\
2000 & $0,17^{*}$ & $0,22^{*}$ & $0,15^{*}$ & $0,28^{*}$ \\
\hline${ }^{*}$ p-valor<0,05. & & & &
\end{tabular}

\section{DISCUSSÃO}

A introdução do vírus do dengue na Bahia, diferentemente de outros Estados como Rio de Janeiro, Alagoas, e Ceará ${ }^{10,11}$, se deu por um município de baixa densidade demográfica. Os casos foram ocorrendo de modo intermitente e a circulação deste agente só passou a se processar de forma rápida após três semanas do diagnóstico do primeiro caso. Considerando que as ações de controle vetorial não estavam estruturadas, não havendo, portanto, ações de ao Aedes aegypti, a epidemia seguiu seu curso natural. No período estudado, a difusão espacial do dengue foi rápida com variações nos agregados considerados, observando-se tanto padrão por contiguidade ou proximidade, como por pontilhado (isolado). Possivelmente, os casos índices das novas áreas afetadas foram provenientes de cidades do próprio Estado da Bahia, muitas vezes atingindo simultaneamente várias cidades, revelando deste modo a velocidade de difusão do vírus, já descrito por outros autores ${ }^{3,4,11,13}$. O fluxo intermunicipal de indivíduos em plena viremia deve ter sido o determinante do aspecto topológico espacial de conectividade ${ }^{14}$ encontrado neste estudo, devido ao importante sistema viário intermunicipal que favorece o intenso fluxo de pessoas, principalmente, em municípios que fazem parte dos pólos dinâmicos da economia baiana, especialmente os turísticos, que naquela época possivelmente estavam densamente infestados pelo Aedes aegypti, conforme constatado pelos níveis de IP registrados.
Como a introdução do vírus se deu por municípios com baixa densidade demográfica, a curva de tendência temporal da taxa de detecção de casos, quando agregada para o estado como um todo, não expressa a intensidade de circulação viral em cada um deles. Isto explica porque o segundo pico epidêmico do estado foi em 1995, quando $21 \%$ dos municípios já haviam sido atingidos. Porém, o que determinou esta elevada taxa de detecção foi o fato de este ter sido o ano em que duas das mais populosas cidades foram mais intensamente atingidas pelo dengue, Feira de Santana e Salvador, que contribuíram com quase $70 \%$ do total de registros da Bahia.

Em Salvador, apesar de não haver registros de casos no sistema oficial de informação, existem relatos de que o vírus já circulava desde dezembro de 1994. Entretanto, os casos foram confundidos com rubéola ${ }^{12}$. Se isto realmente aconteceu significa que o vírus do dengue, após um período inicial de intermitência na detecção de casos, se difundiu de forma muito rápida no território baiano, pois, já no primeiro ano, este agente parece ter percorrido $624 \mathrm{~km}^{2}$ atingindo as populações residentes ao longo deste trajeto.

Em 1996, a velocidade de difusão se manteve de modo que, no final deste ano, cerca de $30 \%$ dos municípios já registravam casos da doença, com maior concentração nas cidades mais próximas do litoral baiano. É importante observar que muitos municípios da mesorregião Sul não mais tiveram registro de dengue, possivelmente devido a redução dos susceptíveis, já que as ações de combate não estavam alcançando níveis incompatíveis com a transmissão, porquanto_outros municípios iam sendo atingidos. Centros urbanos de médio porte, a exemplo de Itabuna e Ilhéus, notificaram milhares de casos naquele ano e, embora a taxa detecção tenha decrescido em Salvador e Feira de Santana, o número de casos nestas cidades ainda continuava elevado sendo, portanto, esses quatro municípios os que mais contribuíram para o delineamento do ápice epidêmico do estado em 1996.

A diminuição da média da taxa de detecção de casos para o estado, ocorrida a partir de 1997, possivelmente, se deveu à diminuição gradativa de indivíduos susceptíveis, principalmente nos quatro dos maiores centros urbanos acima citados, que reduziram cerca de $70 \%$ o número de notificações quando comparado ao ano anterior. Na realidade, do ponto de vista epidemiológico, o que se verificou foi um agravamento da situação, com dispersão progressiva da doença, e manutenção dos elevados índices de IP na maioria dos municípios com registro deste indicador. Entre 1995 e 1997, quase que quadruplicou o número de municípios atingidos, detectando-se casos em todas as mesorregiões do estado, o que significa que foi se estabelecendo o risco de ocorrência de dengue hemorrágico para as populações residentes em distintas áreas do Estado da Bahia. Foi nesta época que se detectou pela primeira vez o sorotipo DENV1, que passou a circular simultaneamente com o DENV2, o que pela teoria das infecções sequenciais ${ }^{10}$, sobretudo o sorotipo 2 sucedendo o 1 ou 3 , se constitui em um dos principais fatores de risco para ocorrência das formas graves da doença, como ocorreu na cidade do Rio de Janeiro $^{15}$. A introdução do DENV3, em 2002, nestas populações que já apresentavam anticorpos para o DENV1 e DENV2, certamente, favoreceu a ocorrência da primeira epidemia de FHD na Bahia.

Após três anos consecutivos, a progressão espacial e temporal do dengue na Bahia apresentou tendência à drástica redução do número de áreas com notificações. Apenas seis municípios permaneceram registrando casos em todos os anos desta série. A curva de tendência na Bahia reafirma o padrão sazonal do dengue, encontrado tanto no 
Brasil, como em outros países das Américas e Sudeste Asiático ${ }^{11,16,17}$. $\mathrm{O}$ vírus circulou em todas as zonas climáticas do estado, incluindo a região árida e semiárida, onde as condições são bastante adversas ao Aedes aegypti, o que revela o seu elevado poder de adaptação. Contudo, a maior intensidade de detecção de casos e expansão territorial foi nas regiões úmidas e semiúmidas do litoral, ideais para a sobrevivência e proliferação intensa do vetor, e também, por serem mais densamente povoadas.

O aparecimento de casos distribuídos de forma dispersa no espaço geográfico do estado e sem continuidade temporal, como ocorreu em outras regiões do país ${ }^{2}$, no início da introdução do dengue em cada município, anunciaram as epidemias que viriam a ocorrer na Bahia. Esse padrão de apresentação, hipoteticamente poderia ter possibilitado o seu controle, ou mesmo a interrupção da progressão viral, o que não se verificou. Para isso, seria necessário não só um sistema qualificado e uniforme de Vigilância Epidemiológica e um eficiente programa de combate ao dengue no estado, mas também a existência de um instrumento efetivo, a exemplo de um imunógeno que pudesse ser utilizado em massa para estabelecer rapidamente imunidade de grupo capaz de impedir a circulação do vírus.

A desestruturação da principal instituição responsável pelo controle do vetor contribuiu para a rapidez da propagação viral. $\mathrm{O}$ programa de combate à dengue apresentava carência de recursos humanos, insumos e equipamentos para implementar as ações. As fortes correlações encontradas entre IP e taxa de detecção indicam a importância do combate vetorial no controle da dengue. Entretanto, não se deve desconhecer que a simples redução dos índices de infestação não impede a circulação viral, conforme já demonstrado por outros autores ${ }^{7,18}$.

Mesmo programas de combate vetorial bem conduzidos do ponto de vista técnico e administrativo, enfrentam dificuldades para alcançar redução da população do Aedes aegypti compatíveis com a eliminação da circulação viral ${ }^{18,19}$, devido às limitações tecnológicas para fazer frente à elevada capacidade adaptativa deste vetor ao ambiente habitado pelo homem.

\section{CONFLITO DE INTERESSE}

Os autores declaram não haver nenhum tipo de conflito de interesse no desenvolvimento do estudo.

\section{REFERÊNCIAS}

1. Kuno G. Review of the factors modulating dengue transmission. Epidemiol Rev 1995; 17: 2 .

2. Tauil PL. Aspectos críticos do controle do dengue no Brasil. Cad Saude Publica 2002; 18:867-871.

3. Teixeira MG, Costa MCN, Guerra Z, Barreto ML Dengue in Brazil: current situation and trends. Dengue Bull 2002; 26: 70-76.

4. Halstead SB. Epidemyology of dengue and dengue hemorrhagic fever. In: Gubler DJ, Kuno G, editors. Dengue and dengue hemorragic fever. CAB International, New York; 1997. p. 23- 44.

5. Medronho RA. Geoprocessamento e saúde: uma nova abordagem do espaço no processo saúde doença, CICT/NECT/FIOCRUZ, Rio de Janeiro; 1995.

6. Cunha RV.Estudo soro-epidemiológico sobre dengue em escolares do Município de Niterói, Rio de Janeiro, 1991. Dissertação de Mestrado, Instituto Oswaldo Cruz, Fundação Oswaldo Cruz, Rio de Janeiro; 1993.
7. Teixeira MG, Costa MCN, Barreto ML, Ferreira LDA, Vasconcelos PFC, Cairnicross S. Dynamics of dengue virus circulating: a silent epidemics in complex urban area. Trop Med Inter Health 2002; 7:757-762.

8. Vasconcelos PC, Mota K, Torres SS, Rosa APA, Tavares Neto J. Epidemia de dengue em Ipupiara e Prado, Bahia. Inquérito soro-epidemiológico. Rev Soc Bras Med Trop 2000; 33: 61-67.

9. Nobre FF. Introdução à análise de dados espaciais, Programa de Engenharia Biomédica, COPPE/UFRJ. Departamento de Estatística, IM, Instituto de Saúde Coletiva, UFBA- Salvador-Bahia. In: Resumos da $32^{\circ}$ Reunião Regional da Associação Brasileira de Estatística. Salvador; 2001. p. 82.

10. Donalisio MRC. O enfrentamento de epidemias: as estratégias e perspectivas do controle da dengue. Tese de Doutorado, Faculdade de Ciências Médicas, Área-Saúde Coletiva. Universidade Estadual de Campinas, Campinas; 1995.

11. Teixeira MG, Barreto ML, Guerra Z. Epidemiologia e medidas de prevenção do dengue. Informe Epidemiológico do Sistema Único de Saúde 1999; 8:4.

12. Teixeira MG, Costa MCN, Barreto ML, Barreto FR. Epidemiologia do dengue em Salvador - Bahia, 1995-1999. Rev Soc Bras Med Trop 2001; 34:269-274.

13. Barreto FR, Teixeira MG, Costa MCN, Carvalho MS, Barreto ML. Spread pattern of the first dengue epidemic in the city of Salvador, Brazil. BioMedCentral Public Health 2008; 8:51.

14. Sá MC, Pina MF, Santos SM. Conceitos Básicos de Sistema de Informação Geográfica e Cartografia aplicados á saúde. Rede Internacional de Informações para a saúde - RIPSA, Editora Organização Pan-americana da Saúde: Representação no Brasil. Ministério da Saúde; 2000. p.120.

15. Casali CG, Pereira MRR, Santos LMJG, Passos MNP, Fortes BPMD, Valencia LIO, et al. A epidemia de dengue/dengue hemorrágico no município do Rio de Janeiro, 2001/2002. Rev Soc Bras Med Trop 2004; 37:296-299.

16. Silveira AC. Dengue: aspectos epidemiológicos e de controle. Rev Soc Bras Med Trop 1998; 31 (supl 2): 5-14.

17. Torres EM. Dengue e dengue hemorrágico, Editorial de lá Universidade Nacional de Quilmes; 1998.

18. Reiter P, Gubler DJ. Surveillance and control of urban dengue vectors. In: Gubler DJ, Kuno G, editors. Dengue and dengue hemorragic fever. CAB International. New York; 1997. p. 425-462.

19. Ooi EE, Goh KT, Gubler DJ. Dengue Prevention and 35 Years of Vector Control in Singapore. Emerg Infect Dis 2006; 12:887-893. 